\title{
CAREER TYPES AND CAREER SATISFACTION AMONG SOCIOLOGY DOCTORAL GRADUATES OF CORVINUS UNIVERSITY
}

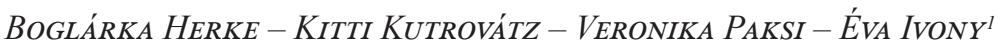

\begin{abstract}
The academic profession has significantly transformed in the past few decades due to the industrialization of higher education and research. Based on sixteen career path interviews, the study investigates how the career paths of sociology doctoral graduates who obtained their master's or PhD degree at Corvinus University of Budapest have been formed within this changing environment of the academic profession. The study distinguishes four researcher career path types and describes attached job characteristics and career satisfaction. Hungarian and international academic researchers have spent most of their careers at Hungarian or renowned foreign universities. Hungarian academic researchers performed a high volume of teaching, while international academic researchers primarily focused on research. The career paths of market researchers were formed by their positions at research firms, where they were involved in applied research projects. Researchers of the mixed career type alternated between the different sectors throughout their career paths that led to dissatisfaction with their careers. Interviewees of the other three types were generally satisfied with their careers, however, the reconciliation of teaching, research and organizational tasks in the case of Hungarian academic researchers, the measurement of publication performance against Western scholars regarding international academic researchers, and the choice between academic and market activities among market researchers all emerged as sources of frustration in the narratives.
\end{abstract}

KEYWORDS: professionals, academic profession, sociology, researcher career paths

\footnotetext{
1 Boglárka Herke is Junior Research Fellow at Centre for Social Sciences, Hungarian Academy of Sciences Centre of Excellence, email: boglarka.herke@gmail.com; Kitti Kutrovátz is Research Fellow at MTA-BCE Social Epidemiology Research Group, email: kitti.kutrovatz@gmail.com; Veronika Paksi is Junior Research Fellow at Centre for Social Sciences, Hungarian Academy of Sciences Centre of Excellence, email: Paksi. Veronika@tk.mta.hu; Éva Ivony, PhD is Associate Professor, Department of Social Work, Theological College of Veszprém, email: evaivony@gmail.com. Research supported by the 'From Talent to Young Researcher. Project aimed at activities supporting the research career model in higher education' (identifier EFOP-3.6.3VEKOP-16-2017-00007), co-supported by the European Union, Hungary and the European Social Fund.
} 


\section{INTRODUCTION ${ }^{2}$}

The academic profession has significantly transformed in the past few decades due to the industrialization of higher education and research (Gumport 2000; Musselin 2008). On the one hand, research funding is increasingly based on personal publication performance, its objective evaluation, and international embeddedness (Evetts 2014; Harley et al. 2004; Musselin 2008). On the other hand, the career paths of researchers have become more uncertain due to the rising number of fixed- and short-term, as well as project-specific contracts that encourage doctoral graduates to build their careers outside the academic sphere (OECD 2012; ESF-Science Connect 2017). Differences can also be observed in the attitudes of academic generations. Younger researchers who were socialized under the new system consider the rules of the transformed academic profession to be clear: they are more motivated to publish in international journals, to build cross-border professional relationships, and to obtain funding for their research. In contrast, older researchers are often more satisfied with their embeddedness in science at a national level and have a greater interest in educational tasks (Kwiek 2015).

Opinions regarding the aim and utility of a profession can also differ among researchers. In sociology - similarly to in other disciplines - the type of research and the sector of employment are also important markers of career paths, and can be sources of professional conflict. In the US, academic sociologists tend to ignore professionals working in practice as they believe that applied sociology lessens the prestige of the profession (Spalter-Roth 2007). Meanwhile, public sociologists, who attach great importance to the dialogue between the public and scholars, often accuse professional academic sociologists of testing only narrow hypotheses and using overcomplicated academic language that is understandable only to professionals (Berger 2002; Patterson 2002). Finally, policy sociology is located between public and professional sociologies, embodying the world of applied research, where sociologists work on demand (Burawoy 2005).

In this study, we investigate how the career paths of sociology doctoral graduates who obtained their master's or $\mathrm{PhD}$ degree at Corvinus University of Budapest (CUB) have been formed within this changing environment of the academic profession. Based on sixteen career path interviews, we explore different career paths/types of researchers, attached job characteristics, and graduates' evaluations of their own careers. We focus on researcher careers, as in line with previous international and Hungarian findings (ESF-Science 2 The authors are grateful to Professor György Lengyel, the anonymous reviewers, and the editors of
the journal for their helpful comments and feedback on earlier versions of this article. 
Connect 2017; Inzelt-Csonka 2018), the results of the career track survey of CUB from 2018 show that around seventy percent of social science doctoral graduates work at universities or research institutes. The rest of them work for the government or in the business sector in equal proportions.

In the following, we first introduce previous investigations into research careers, then briefly review the methodological background of our research. Afterwards, we move further to the results, distinguish four different types of research career paths (Hungarian academic, international academic, market, and mixed), and describe their main features based on their major stages, individual positions obtained as teachers, researchers, and at the managerial level, work-life balance, and evaluations of career paths and future aspirations. We conclude our study with a summary.

\section{TYPES OF RESEARCH CAREERS}

Relatively few empirical studies have investigated not only the start of a career in science (e.g. Fox-Stephan 2001; Lindholm 2004), or career transition (e.g. Barabasch-Merrill 2014; Mulvey 2014), but the entire research career. Below, we present related findings of an international (Angervall-Gustafsson 2014) and two Hungarian studies (Inzelt-Csonka 2018; Pálinkó 2010).

Angervall and Gustafsson (2014) identified two career types of young researchers working in the field of educational sciences using semi-structured interviews: namely, successful researchers, as well as responsible and supportive researchers. Successful researchers build high-level research careers due to a conscious process of construction and associated institutional support, and have international publications. In addition to research, they teach and conduct advisory, review-, and opponent-based activity, but their researcher identity is more prominent. Responsible and supportive researchers, on the other hand, are characterized by their working as teachers or social workers prior to graduation, while after graduation they become employed in higher education. They are usually dissatisfied with their research careers, are excluded from professional networks, have no institutional support, and have no time for research alongside teaching, while academic career advancement is closed to them. These results confirm previous findings about the gradual differentiation of the less active researcher role with a greater educational burden, and the active researcher role (Harley et al. 2004; Musselin 2008).

Pálinkó (2010) distinguished four ideal types of research careers based on semi-structured and narrative focus group interviews with biologist researchers. 
Automatic job receivers immediately get a job in a Hungarian academic research facility or at a university after completing their $\mathrm{PhD}$, and measure their scientific performance against their Hungarian colleagues. The second type includes those going abroad. They find employment in the international academic sphere immediately after graduation. They have high professional expectations, are particularly interested in research jobs, and measure their performance against international colleagues. Those distant from research constitute the third group. These individuals do not get appropriate researcher status after returning from abroad, so they work in middle-management positions in the industrial sphere. They later move away from a research career. Survivors have to wait for the right job, as vacant researcher positions are not available for them after obtaining a $\mathrm{PhD}$ degree. They try to get through this transitional period in a compromised academic position.

Inzelt and Csonka (2018) investigated the career paths of PhD holders in the field of social sciences and humanities based on administrative data, interviews, and an online survey. In addition to the two main internationally accepted career path types (working inside and outside the academic sphere), they identified four subtypes they called "career mobility schemes," "pre-doctoral job keepers," "post-doctoral job keepers," "intra-sector job changers," and "cross-sector job changers."

In our study, we rely on these earlier typologies, but we distinguish career path types based on our empirical data. In the following, we describe our method of analysis in detail.

\section{DATA AND METHODS}

Our qualitative research was part of a broader project initiated by Corvinus University of Budapest conducted in the spring of 2018. First, a survey was sent out to graduates of all doctoral schools of the institute to track their careers. Second, at the Sociology Doctoral School, we complemented this quantitative research with interviews in order to better understand the formation of the career paths of sociologist $\mathrm{PhD}$ graduates who work as researchers.

We conducted sixteen career path interviews. Most of the interviewees obtained their $\mathrm{PhD}$ degree at CUB (or at one of its predecessor institutes), but the sample also contained two sociologists who did their master's studies at CUB but obtained their $\mathrm{PhD}$ at a non-Hungarian university. They were added to the sample to help map the career formation of those former students who had selected a non-Hungarian doctoral school for their studies. In addition, 
there was one interviewee who finished her university studies at CUB before the introduction of the new doctoral training system in the 1990s, and who obtained a candidate of sciences degree under the old system at the Hungarian Academy of Sciences. Having CUB as an alma mater, either regarding master's or $\mathrm{PhD}$ studies, however, was a common characteristic of the interviewees. Furthermore, as sociology could be studied only as a specialization of training in economics at this university until the 2000 s, most of the interviewees had obtained a joint master's degree in economics and sociology.

All sociologists were partially or fully engaged in a research career. Those who were very detached from research and were pursuing careers in the government or business sector (such as politicians or analysts, etc.) were not part of the target group, as the aim of the research was to explore researchers' careers. The interviewees were selected through a targeted stratified sampling procedure to cover the core population in terms of gender, age, geographical location (capital and city-rural region), and workplace. The sample included nine men and seven women. Most of them were in their mid-forties, four were in their fifties, while the two oldest interviewees were between 60 and 70 years old. Most of the interviewees had a family. Everyone worked in Budapest, except for two interviewees who periodically commuted from the countryside to Budapest. One interviewee was retired.

We conducted career path interviews that mainly relied on the narratives of the interviewees but we also asked questions tailored to our pre-established research goals. For the analysis, we used the narrative analysis method (Remmik et al. 2013): we read the interviews several times to identify common and unique elements of career paths. The stories told during the interviews were arranged in chronological order. Then, from the perspective of the narrator, we explored the interviewee's career report and supplemented it with data from biographical documents (CVs) as well as using our own knowledge (based on the interviewerinterviewee relationship) (Merrill-West 2009).

Similar to earlier career path research (Angervall-Gustafsson 2014; Pálinkó 2010), different career types were identified by comparing narratives. The types thus distinguished are based on our empirical data, do not represent pure ideal types, and may not be generalized to all sociologists with a $\mathrm{PhD}$ degree. These types rather indicate potential career paths for researchers in this field. 


\section{RESULTS: RESEARCH CAREER TYPES AMONG SOCIOLOGY DOCTORAL GRADUATES}

The most important distinguishing aspects were sectoral location (academic or market sphere), movement between the sectors, and attachment to Hungary. Our types, therefore, not only help map mobility paths between sectors, as in the study of Inzelt and Csonka (2018), but similar to Pálinkó's (2010) study also take into account attachment to Hungary.

The four identified career paths are (1) Hungarian academic, (2) international academic, (3) market, and (4) mixed research careers. In the following, we will provide a detailed overview of these career paths based on their major stages, individual positions obtained as teachers, researchers, or at the managerial level and their reconciliation, work-life balance, and an evaluation of career paths and future aspirations.

As most of the interviewees had a joint master's degree in economics and sociology, or a master's degree in economics, we also describe the role of having a degree in economics in the formation of sociologist researcher career paths. Furthermore, we highlight the gender of the interviewees, as - in line with previous literature (Allard et al. 2011; Knudsen 2009; Paksi et al. 2016; Wattis-James 2013) - we found that work-life balance varied in the career paths of the two genders. Finally, we also mention some other socio-demographic characteristics (e.g. generation, and social position), insofar as we found that these factors played a role in the formation of the career paths.

\section{Hungarian academic career}

The Hungarian academic career was the first and most unambiguous career path. Individuals with this type of career started working in research and/or teaching positions in a Hungarian higher education or academic institution relatively soon after graduation. A common feature of the latter involved combining research, teaching, and managerial/organizational roles. These different roles were present in varying intensities throughout the careers of such individuals. These career paths can be described as taking advantage of opportunities rather than conscious career building. Although shorter experiences abroad, international projects, and relationships appeared in the career paths, the embeddedness of this type into domestic professional networks was stronger. All six interviewees in this group had either a joint master's degree in economics and sociology, or a degree in economics, and five of them were women. At the time of the interviews, four interviewees were associate 
professors and two of them were professors. One of them had a second part-time job as a senior research fellow at an academic research institute.

As stated above, different roles - researchers, educators, and managers - were fulfilled in parallel, and the interviewees achieved success in all areas. On the one hand, the latter mentioned that research and education fit together well and complement each other. For example, courses could often be tailored to specific research projects. On the other hand, interviewees also highlighted that teaching and especially related organizational tasks took time from research. For this reason, it was not uncommon that one area or another appeared more prominently in their career paths.

Generational differences also appeared in relation to the researcher-educator identity. Publishing was the primary activity and the basis of success from the beginning of the careers of the youngest representatives of this career path type. Members of the older generation, on the other hand, pointed out that having a conscious career-building or publishing strategy was less of a requirement for them.

The duality of teaching and research was also a challenge in terms of Hungarian embeddedness. The prestige of the two professions has depended on and changed according to the social and historical context. The following quote highlights this issue and the teaching-related burden:

(...) and then I was dreaming again about how great it would be to get into the Academy. ${ }^{3}$ I declined it because I thought that going to the Academy was for losers, but in the meantime I realized that there was no cooler job than the Academy, because you can receive the same basic salary as at the university, but there are no students there. (Interviewee 8, Male)

The interviewees struggled with another duality - namely, the reconciliation of work and private life. This was mainly mentioned by interviewees who had small children at the time of graduating and starting their careers. Parents reported difficulties balancing the different areas and they usually pushed research tasks to the background.

Also connected to having children is the fact that many interviewees emphasized the importance of flexible and home-based work. A quote from a mother of four children summarizes the benefits of working as a researcher:

3 Hungarian Academy of Sciences 
How can it be reconciled?... well, it is very hard, it takes a lot of organization... but if I had not started working in the university sphere but instead had gone into the market sphere, then I would surely have been in a decision situation about whether to choose family or work. (Interviewee 15, Female)

Flexible working, however, was perceived as a disadvantage as well, due to "endless work." One interviewee, for example, was forced to take one year of unpaid leave because she had become exhausted from the huge amount of work involved in having a senior leading position at a university.

Researchers with this career path type had a very mixed view of their careers. First, some of them were satisfied with their development so far. They mentioned external determinants, especially a supportive and inspirational environment, and good co-operation at their workplaces. Only one interviewee highlighted the importance of her own merits, and structured and disciplined work. She also considered her career to be unique because of her 'advocacy' activities. It is a characteristic of this type of career path that individuals measured their success using far fewer objective measures of scientific performance. Second, other interviewees of this type clearly expressed their dissatisfaction with their research careers. They mentioned that they had not achieved their goals as researchers, and maybe they should have decided differently in the past and built their careers more consciously. Most noticeable was the dissatisfaction of an interviewee who had not had time or energy to build her research career because of her high level position at a university.

We used to say that nobody would ever thank me in this life, because everyone will calculate how many publications I have, what research I have done, how much money that is worth, etc. But how the university faculty was built, or how international training was started, how faculty marketing was strengthened, what programs were created within this dean's cycle, we might notice them, but in the end, everyone else will say 'all right, and what about publications?' (....) (Interviewee 16, Female)

Some of the interviewees also reported on the positive effects of having a degree in economics on their research career as sociologists. For instance, one of them found it beneficial that she could combine economic and sociological knowledge in her research, while another researcher highlighted the high prestige of the degree in economics that had helped him to gain recognition when working together with economists. 
Regarding professional aspirations and plans, members of this group most often formulated medium-term research plans, such as wishing to complete an ongoing project or to explore a new research topic. Depending on in which area they felt they were weaker, they planned to reinforce their identity either as lecturer or researcher. There was a need for career advancement in both areas interviewees aimed to habilitate and obtain the title of Doctor of Science. Only one researcher stated that they aimed to make a lasting contribution to science and to obtain international recognition. In one case, the idea of going abroad arose.

\section{International academic career}

Researchers with an international academic career type were internationally mobile even during the time of their university and $\mathrm{PhD}$ studies, and their interest in sociology was identified and reinforced by both Hungarian and international teachers. Receiving one or more scholarships from prestigious American or European universities, they partly or completely pursued their PhDs abroad. Their professional careers were much more consciously planned than the careers of Hungarian academic researchers. All three researchers belonging to this group were men in their forties, and all had a joint master's degree in economics and sociology. At the time of the interviews, all of them had returned to Hungary and were working as associate professors at universities in Hungary, and one of them also had a position as a senior research fellow at an academic research institute.

Their career paths were characterized by conscious planning, but in their case we also encountered some decisive decision-making situations. These included whether to take up a position in the government sector as an economist, which would have meant better financial conditions, or whether to follow their original professional interest as a researcher. One of them described his dilemma as follows:

I asked myself, how would I make a living out of this? I have a degree in economics, and all of my former classmates here quickly found themselves in important positions while earning more money, and here I am now - anxious to decide whether to read the files here... or to do what I am interested in, but who knows if I will ever make a living out of it. (Interviewee 5, Male) 
Professional networks played an important role in each interviewee's career: apart from their strong motivation and excellent achievements, cooperation between institutes, individual college contacts, and their international publications and conference attendances created international opportunities, which built upon each other. Their networks helped them to get positions at Western European or American universities.

Actually, these two fellowship periods allowed me to finish a couple of PhD articles, and in the meantime I was asked if I could apply for a postdoc, so they actually created an application for me. (Interviewee 13, Male)

However, even international experience did not automatically guarantee a job, either in Hungary or abroad. The following interview quote highlights the relevance of opportunities and luck as a factor:

I think it was an eternal question at that time, so even as a graduate $P h D$ it was still so uncertain whether one could find a job. Jobs were not just given to anyone in Hungary either, so it was really fortunate that there was a job here just then. But then there were 7-8 years when there was no opportunity to employ a new person at the department, and a generation gap was thus created (...). It is quite incidental when job opportunities are available, and a lot of things depend on the European market too. In hindsight, postdoc jobs are there, you just have to find them. (Interviewee 13, Male)

All of the interviewees maintained their international relationships, and their work in Hungary has linked them to the international scene ever since. Many had chosen an area or approach to a PhD topic that was well suited not only to particular sociologies, but also to other disciplines and areas, especially abroad. They maintained their research topics throughout their careers, and they mostly worked with foreign professionals, while their domestic network was less extensive. The latter derived not only from their orientation but also from the marginal position of their topic or preferred methodology in Hungary. At the same time, they strove for domestic professional integration as well.

While each researcher undertook teaching tasks, they all preferred research. Those with more research tasks coordinated the two fields quite easily. Teaching appeared to be a constraint in one interviewee's life - he did not consider himself a good teacher, and did not like teaching as such. However, a certain attachment to education could be identified when he said that he regretted that he had 
not been able to teach subjects related to his specialty in Hungary, because despite his international experience - those subjects were taught by more senior teachers in Hungary. A researcher who took a more active educational role found it difficult to reconcile his tasks with research. Meanwhile, he had strived to achieve balance because he found it important to train students and monitor their careers. Nevertheless, these professionals in our sample were forced to choose between the two tasks at a later career stage because Hungarian or European research grants had defined the time available for the two activities. These choices, however, were mostly welcomed by the interviewees, since they preferred research over teaching.

All international academic researchers were married, their spouses worked in the same profession, and they had children. Reconciling work and private life was not a challenge for the interviewees after returning to Hungary. They all utilized the flexible working conditions and family-friendly environments of universities and research institutions. However, when working abroad, the birth and education of their children were key issues in their work-life balance. International academic researchers' professional life events were subordinated to the anticipated time of birth of children - for example, interviewees had delayed scholarships because they wanted their children to be born in Hungary, or they had wanted to seize the opportunity to get more experience abroad before the planned arrival of their next child. Regarding their wives' career paths, those were almost entirely subordinated to husbands' professional careers. In contrast to the situation in Hungary, wages in Western Europe made it possible to have a single-income household. Two wives of interviewees were also educators and researchers, although they played the role of housewives abroad. However, reasons for returning home included not only the schooling of children but starting or continuing wives' careers.

Researchers in this group were fundamentally satisfied with their careers. Despite this, they measured their performance against that of members of the international research community, thus their career evaluation lead to discrepancies. One of them measured success in terms of publications, and was dissatisfied with the result: "it is very difficult to achieve from here on the periphery" (Interviewee 10, Male). It was common that international academic researchers could not plan their careers for the long term. Their plans included publishing more research findings, obtaining the title of Doctor of Science of the Hungarian Academy of Sciences, implementing numerous research ideas, participating in further international projects, and - in one case - searching for a new position abroad. 


\section{Market research career}

In relation to the career paths of market researchers, an applied research profile was dominant, but researchers of this type were also associated with the academic sphere in numerous ways. Working in the market sphere was determined by the availability of a job at an early stage of their professional careers. The latter worked for a long time at the same company or research institute, where they could deal with areas that coincided with their professional interests. Three of the four interviewees in this group were men, and all of them either had a joint master's degree in economics and sociology, or a degree in economics. At the time of the interviews, all of them were working at private research institutes / international organizations, while at earlier phases of their careers some of them worked at government research institutes or market companies that were not specialized in research.

Due to their duties and responsibilities at work, doctoral studies were usually not started immediately after graduating. These interviewees already had significant professional experience at enrolment, which was considered an advantage in meeting requirements. They were much more aware of their research preferences and could better synthesize the knowledge they accumulated during their education. One of them explained the situation as follows:

And now it was good, both when I graduated and after that, to have hands-on experience, and I had already seen how organizations work, how diplomacy works, and so on. So that I had been in contact with quite a few stakeholders to see scientific theories through a kind of practical prism in that sense. (Interviewee 12, Male)

The choice of doctoral topic was influenced by the tasks and research topics completed at the workplace, so besides supervisors, colleagues and superiors were also often mentioned as an intellectual influence. These interviewees not only used the experience they obtained at the workplace, but also used data available there to write their dissertations.

They remained in the market sphere after completing their PhDs, and most of them also remained at the same companies. As a result, they did not think that obtaining a doctorate had made a significant difference in their professional careers, but they rather considered it a formal title that would allow them to return to the academic sphere if needed.

Although they sought a link to the academic sphere, their perception of the academic environment was varied. On the one hand, we identified a kind of 
separation from formal science. In this respect, the interviewees criticized the fact that the Hungarian scientific profession appreciates texts that are formulated in a more complicated way, which makes the understanding of findings difficult for the public. They also complained that in many cases formality is considered a more important aspect than content. All of this highlights the difference in the target audience: market researchers make materials primarily for non-professionals, therefore public comprehensibility is much more important in their work. One of them criticized formal science as follows:

Correct spelling rules and literary references are almost more important than having some sense of what they are describing. (...) If I write a study, I get it back with comments that it has a tabloid smell (...), the more boring it is, the more 'scientific' it is. (Interviewee 1, Female)

On the other hand, a need to return to the academic world was also perceived, so some interviewees were trying to suppress their market-related activities and increase their scientific activity as much as possible. For some of them, teaching was the first step in returning to the academic community. They, however, also gave university lectures because the courses were closely related to their research activities or to a field that was prominently a part of their careers. Interviewees of the market researcher type were also tied to the formal scientific community in other ways, as even non-educators were regularly asked to review scientific papers, and they often published in scientific journals.

Most interviewees in this group had also had leadership roles at some stage of their career path. Some of them had even started their own businesses, where they carried on their previous activities according to their individual preferences. In their case, entrepreneurial insecurity often appeared to be characteristic of their career paths. For instance, they highlighted their unpredictable monthly income, unlike that associated with a teaching career. Leadership tasks, furthermore, resulted in less time for teaching and research, but also for private life.

Starting doctoral studies at a later age also caused difficulties regarding the reconciliation of work and family life, as many of them already had children while completing their studies. One of the interviewees explained that in order to write her dissertation while working, she had to relegate her private life to the background, which created a very difficult time for the family.

Market researchers were generally satisfied with their careers and considered work in the private sector as a positive thing, as they could learn about applied research. One of them highlighted its advantages as follows: 
It is an attraction in the sense that it is much more important for applied research that it is not the researcher who is asking the question, but the researcher's client, and then it is the researcher's responsibility to answer the research question in a suitably chosen way. The client can be the state administration, one of the ministries, and in many cases is the private sector and international organizations. (Interviewee 11, Male)

The advantage of having a degree in economics was also mentioned regarding market activities. For instance, one interviewee explained that economic knowledge had helped her with leadership tasks. Furthermore, another interviewee emphasized that sociology and economics could hardly be separated in practice, and because he used these two kinds of knowledge together in his work, it created a much broader perspective for him compared to his economist colleagues.

However, frustration also emerged during the interviews, some of which was related to the market-related activities of the interviewees. For example, the latter mentioned the lack of state support - namely, that their private companies were conducting the type of research that should be the responsibility of the state. On the other hand, there was a feeling of something lacking in connection with the careers of researchers who sought to return to formal science. They said that they would be way ahead in their scientific career if they had made a different decision at the start. Nonetheless, they did not regret their earlier decisions, and instead were focused on their plans. Some of them identified plans related to their company, such as stabilizing returns, or developing the methodological apparatus. Other interviewees planned to write books and highquality publications, as well as strengthen their international connections.

\section{Mixed research career}

Unlike researchers of the international academic type, the careers of mixed researchers were characterized by slow career advancement, and full-time, peripheral jobs that lacked professional embeddedness, resulting in a constant sense of frustration. Two interviewees in this group were men, and one was a woman. Two interviewees had a master's degree in sociology, and one had a master's in economics. Moreover, two of them had an additional master's degree in another discipline. At the time of the interviews, one of them was taking a one-year period of unpaid leave from a research position at a university; another interviewee worked at a market research company, while the third interviewee was a retired associate professor. 
The development of the interviewees' professional careers was primarily characterized by late or ad hoc specialization and the lengthy acquisition of doctoral degrees. Their primary choice of profession either involved a sudden decision or a different discipline, and was motivated in some cases by their family milieu and values, or even caused by a breakup with the latter, while in other cases it was due to the effects of the political system change. Based on their narratives, the rapid socio-economic transformation in the 1990s brought about by the regime change did not allow them to acquire those additional skills that enabled students from the upper-middle class and higher social groups to pursue a barrier-free, smoother research career. Their decisions regarding their studies, therefore, were not made as a result of conscious careerbuilding. After obtaining a first university degree, their career progression was determined by the completion of a second degree, family formation, and independence after graduation. The interviewees did not work or worked only for a short period in the field of their first degree, and were able to enter the labor market in other specialties. Their full-time jobs supported them by providing an existence, but the lack of time for studying significantly limited the circumstances of their late specialization, leaving them with little time to become familiar with the new field of science (sociology). One interviewee summarized this issue in relation to obtaining a $\mathrm{PhD}$ while holding down a full-time job outside of academia:

... So, my difficulty was that the work I had at that time was not about my research, so my research - but that was [also] already the case with my doctorate and PhD - was not related to my actual job. So, if I had had some kind of status at the Institute, I would probably have written my dissertation much more easily. But first I had to earn some money, and then, quasi in my free time, I did the research from which I wrote my dissertation. (...) ... So there was this kind of duality because this was not my main topic at my main job... .

(Interviewee 6, Female)

Researchers of this type, therefore, took a long time between obtaining a master's degree and their doctorate - in most cases, this took 20 years. In the case of one interviewee, for whom sociology was the primary field of study, it took 10 years to complete a $\mathrm{PhD}$, but this was accompanied by commitment to a research topic and a high degree of personal motivation. In other cases, obtaining a doctoral degree was motivated primarily by work obligations and not by individual interests, as the following quote highlights: 
I did the doctorate because it was my job obligation. Otherwise, I would never have done it. I could have published without it. I did also publish. My books were published. (...) so I started my doctorate in 1998. In 1998, they told me to either obtain a doctorate or go away... so I said I would do it. (...) I wanted to close this research area... it was not a start for me, it was rather a closure. (Interviewee 7, Male)

Another characteristic of the mixed career path was a minimal or total lack of professional embeddedness. Several factors influenced the development of a professional network. For instance, one of the interviewees was not integrated into the research projects of the alma mater institution during his university years, nor did his research topic fit into the scientific workshops of the university. He was only involved in another university's doctoral program. For another interviewee, obligations at work (namely, preparation for research projects in different topics) did not provide an opportunity for further study in the latter's research field. Therefore, she was not able to achieve more with her research, appear at national or international conferences, or participate in workshops of international research groups.

Interviewees with this career path perceived that the factor they described as a "negative institutional environment" had played a significant role in their having a marginalized researcher career path. On the other hand, the mixed research career alone did not hinder the publishing activity of any of these researchers - all of them had published studies in scientific journals, and had either co-authored or single-authored books. Their activity, however, can be said to be irregular both in terms of topic and frequency.

Over the past decade, a lack of further development in their field of research, a peripheral research topic, a non-specialist workplace, and a lack of professional embeddedness have caused cumulative disadvantages for researchers of this type. Their knowledge in the field of science and the doctoral training, however, made it possible for them to take advantage of opportunities that arose in different spheres. They alternated between the market sphere, university research projects, politics, or the public sphere, resulting in a "drifting" career path. Unlike interviewees of the other types, two researchers of the mixed type did not have a degree in economics, therefore they could not rely on that knowledge. The lack of expansion of their research area, its peripheral nature, and workplace failures all led the interviewees to experience a periodic or a constant sense of frustration and a sense of distance from their profession and academic career. The following quote is a good example of this feeling: 
... So, I was left out everywhere, I have to say. I have not become a researcher because I didn't want to [i.e. this was not the reason] - I really wanted to be a researcher, but I haven't really had the opportunity (...) to this day, I'm still waiting for this big opportunity. I practically graduated in 2006 and have been on hold since then. (Interviewee 2, Male)

In one case, abandonment of the profession was also mentioned. Another interviewee took up employment at a higher education institution after finalizing his $\mathrm{PhD}$ at a later age, and worked there as an instructor until his retirement. Nevertheless, he did not consider his career to be a research career. The interviewees briefly talked about their research plans. Compared to their original doctoral topic, the new topics were either peripheral, or they were not planning to conduct any research at all.

\section{CONCLUSION}

In our study, we examined researchers' career paths, job characteristics, and career satisfaction in the field of sociology. Our research was based on the analysis of sixteen career path interviews with researchers with a $\mathrm{PhD}$ degree in sociology with a connection to Corvinus University of Budapest. We defined four types of career paths, which we created based on previous empirical results and elements identified during the analysis.

The first career path we identified is the Hungarian academic. Researchers of this type started working in research and/or teaching positions in Hungarian higher education or an academic institution relatively soon after graduation. Their careers were rather shaped by opportunities that arose, but not conscious career building. Education and the organization of education played a significant role in their careers, and research activity was less dominant. The second type is made up of international academic researchers who spent a significant amount of time abroad during their university years and during their $\mathrm{PhD}$ studies, while later they received jobs at renowned Western European or American universities, or at an international university that was based in Hungary. Their professional careers were much more consciously planned than the careers of Hungarian academic researchers. They also gave university lectures, although their primary professional activity was research.

These two types of academic careers (Hungarian and international) strongly vary according to the individuals' attachment to Hungary. Their researcher 
identity, professional expectations, and especially reference groups - as in Pálinkó's (2010) classification of "automatic job receiver" and "going abroad" groups - were significantly determined by their affiliation to a Hungarian or foreign institution. In the case of our international academic type, the results also echo Kwiek's (2015) findings for younger Polish researchers. International academic researchers are also members of the younger generation who were socialized after the change of regime, and who are well-adapted to the changes and new rules of the academic profession. In addition, our international academic researchers are comparable to the successful researcher type identified by Angervall and Gustafsson (2014), whose research careers are dominated by conscious career-building and international publications. They received significant institutional support, while researchers of the Hungarian academic career type often did not have time to pursue research that would have permitted them to enter the international scientific field. Thus, the duality of the teacherresearcher role (Harley et al. 2004; Musselin 2008) was mainly manifested in the narratives of Hungarian academic researchers. This also raised the issue of publication pressure, and -similarly to with supportive researchers (AngervallGustafsson 2014) - dissatisfaction was mainly due to their lower level of publication performance. In contrast to the results of Angervall and Gustafsson (2014), however, we found that international academic researchers were also somehow dissatisfied with their achievements so far, which is explained by the fact that they measure their performance against that of Western researchers.

In the case of Hungarian academic researchers, who were mainly women in our sample, the burden of being young parents, a lack of time, and the stress of reconciling work and family life were influential factors. However, the flexible working conditions available in research positions were partially able to mitigate these difficulties. These results are consistent with previous domestic and international experience (Knudsen 2009; Paksi et al. 2016; Wattis-James 2013). Difficulties with achieving work-life balance, especially the timing of life events, also emerged in the narratives of international academic researchers (consisting only of men in our sample).

In relation to future plans, we found that researchers of the international and Hungarian academic career types primarily aimed at advancing in the scientific hierarchy. It was common to them that, given the importance of professional networks (Adams et al. 2005), neither type was satisfied with their degree of embeddedness. Hungarian academic researchers mainly aimed to build relationships with foreign partners, while those with stronger international ties wanted to develop their domestic professional embeddedness.

The third type we identified is the market researcher career path, within which an important element is the applied researcher identity. Researchers 
with this career path were employed at market companies or research institutes outside the Academy. Working in the market sphere was determined by the availability of jobs at an early stage of their professional careers. Most of them were also engaged in review activities or teaching at a higher education institution, although this was limited to one or two courses per year. In general, they sought a link to the academic sphere, but in the narratives of some interviewees, we discovered a kind of separation from the formal scientific environment, which reflects the conflict between public and professional sociology (Berger 2002; Burawoy 2005; Patterson 2002). While market researchers correspond more to the policy sociologist type of Burawoy (2005), their target audience, who are usually not professionals, appears to encourage a public sociologist identity. Leadership roles were also frequent elements of this career type, therefore the issue of work-life balance mainly arose in narratives regarding the reconciliation of managerial tasks and family life. Their future objectives consisted of plans related to managership, teaching, and research.

Finally, we defined a mixed research career path, the most characteristic feature of which was that the material livelihood of these researchers was not supported by activity in a discipline that was their primary focus. Despite this, we defined these careers as research careers because the individuals in this group had a loose relationship with the university/academic community and their field of science. Interviewees of this type were those most likely to have experienced the uncertainties associated with the transformation of the academic profession (OECD 2012; ESF-Science Connect 2017). Their careers could not be associated with one sector or one institution, in contrast to the other three types; they alternated between the market sphere, university research projects, politics, and the public sphere and were often employed in fixed-term research projects that were not their primary scientific interest.

Similar to the international academic type, in the case of the mixed career type the effects of the change of the political system on careers could also be observed - in this case, however, the interviewees reported the negative effects of the rapid socio-economic transition. Sociologists with careers of this type did not have the opportunity to effectively overcome their disadvantages in relation to their fellow students from more advantaged social groups. The drifting career path, furthermore, was caused by factors such as late and ad hoc specialization, unconscious career building, a lack of attachment to institutions (either academic or non-academic), a low level of scientific embeddedness, and a marginal research topic. The period of late specialization also coincided with the time of family formation in the case of some of the interviewees, although work-life balance did not emerge as a major issue in the narratives 
of mixed researchers. We heard less about future plans for the mixed type, although changing their current peripheral situation was a standard plan for the future.

To sum up, the changes in the academic profession were manifested in the narratives in several ways. Frustration regarding not having enough time for research due to educational and organizational tasks affected Hungarian academic researchers; the importance of international experience (and consequent embeddedness in international networks) was typical of international academic researchers; and the uncertainties of having project-specific contracts experienced by mixed researchers are all associated with these changes. These changes were less salient in the career paths of market researchers, who mainly worked outside the academic sphere. Market researchers were also those individuals who typically experienced the advantages of having a degree in economics and sociology, as they could combine these two kinds of knowledge in both market activities and research.

The four career types distinguished here are based on a small sample narrowed down to one university, thus limiting the transferability of results. Our interview partners, however, were probably socialized in more or less the same professional environment as their cohort and colleagues in other Central and Eastern European (CEE) countries, where the management of science involves many similarities due to the common social-historical development of these ex-state-socialist countries. Further studies might extend the investigation to the regional level, and compare sociologists' career paths on a country basis.

\section{REFERENCES}

Adams, J. D. - G. C. Black, J. - R. Clemmons - P. E. Stephan (2005) Scientific teams and institutional collaborations: Evidence from U.S. universities, 1981-1999. Research Policy, Vol. 34, No. 3., pp. 259-285, DOI: 10.1016/j. respol.2005.01.014.

Allard, K. - L. Haas - C. Ph. Hwang (2011) Family-supportive organizational culture and fathers' experiences of work-family conflict in Sweden. Gender, Work \& Organization, Vol. 18, No. 2., pp. 141157, DOI: 10.1111/j.14680432.2010.00540.x

Angervall, P. - J. Gustafsson (2014) The making of careers in academia: Split career movements in education science. European Educational Research Journal, Vol. 13, No. 6., pp. 601-615, DOI: 10.2304/eerj.2014.13.6.601 
Barabasch, A. - B. Merrill (2014) Cross-cultural approaches to biographical interviews: Looking at career transitions and lifelong learning. Research in Comparative and International Education, Vol. 9, No. 3., pp. 287-300, DOI: $10.2304 /$ rcie.2014.9.3.287

Berger, P. L. (2002) Whatever happened to sociology? First Things, October 2002, http://www.firstthings.com/article/2002/10/whatever-happened-to-sociology [Last access: 0707 2020]

Burawoy, M. (2005) For public sociology. American Sociological Review, Vol. 70, No. 1., pp. 4-28, DOI: 10.1177/000312240507000102

ESF-Science Connect (2017) Career Tracking Survey of Doctorate Holders. Project Report. Strasbourg, European Science Foundation - Science Connect, http://www.esf.org/fileadmin/user_upload/esf/F-FINAL-Career_Tracking Survey_2017_Project_Report.pdf [Last access: 0123 2020]

Evetts, J. (2014) The Concept of Professionalism: Professional Work, Professional Practice and Learning. In: Billett, S. - Ch. Harteis - H. Gruber (eds.): International Handbook of Research in Professional and Practice-Based Learning. Dordrecht, Springer, Netherlands, pp. 29-56, DOI: 10.1007/97894-017-8902-8 2

Fox, M. F. - P. E. Stephan (2001) Careers of young scientists: Preferences, prospects and realities by gender and field. Social Studies of Science, Vol. 31, No. 1., pp. 109-22, DOI: 10.1177/030631201031001006.

Gumport, P. J. (2000) Academic restructuring: Organizational change and institutional imperatives. Higher Education, Vol. 39, No. 1., pp. 67-91, DOI: 10.1023/A:1003859026301

Harley, S. - M. Muller-Camen - A. Collin (2004) From academic communities to managed organisations: The implications for academic careers in UK and German universities. Journal of Vocational Behavior, Vol. 64, No. 2., pp. 329-345, DOI: 10.1016/j.jvb.2002.09.003

Inzelt, A. - L. Csonka (2018) A PhD-fokozatot szerzettek karrierje a társadalom- és humán tudományokban. Educatio, Vol. 27, No. 1., pp. 30-45, DOI: $10.1556 / 2063.27 .2018 .1 .3$

Knudsen, K. (2009) Striking a different balance: Work-family conflict for female and male managers in a Scandinavian context. Gender in Management: An International Journal, Vol. 24, No. 4., pp. 252-269, DOI: $10.1108 / 17542410910961541$

Kwiek, M. (2015) Academic generations and academic work: Patterns of attitudes, behaviors, and research productivity of Polish academics after 1989. Studies in Higher Education, Vol. 40, No. 8., pp. 1354-76, DOI: 10.1080/03075079.2015.1060706 
Lindholm, J. A. (2004) Pathways to the professoriate: The role of self, others, and environment in shaping academic career aspirations. The Journal of Higher Education, Vol. 75, No. 6.,pp. 603-635, DOI: 10.1080/00221546.2004.11773579

Merrill, B. - L. West (2009) Using Biographical Methods In Social Research. London, SAGE Publications, Ltd. DOI: 10.4135/9780857028990

Mulvey, R. (2014) 'While I'm retraining, I get the full whack': Illuminating narratives of career change. Research in Comparative and International Education, Vol. 9, No. 3., pp. 328-340, DOI:10.2304/rcie.2014.9.3.328

Musselin, Ch. (2008) Towards a sociology of academic work. In.: Amaral, A. I. Bleiklie - Ch. Musselin (eds.): From Governance to Identity. A festschrift for Mary Henkel. Dordrecht: Springer, pp. 47-56, DOI: 10.1007/978-1-40208994-7_5

OECD (2012) Careers of Doctorate Holders. Key findings of the OECDKNOWINNO Project on the careers of doctorate holders. http://www.oecd. org/sti/inno/CDH\%20FINAL\%20REPORT-.pdf [Last access: 0123 2020]

Paksi, V. - B. Nagy - G. Király (2016) The timing of motherhood while earning a $\mathrm{PhD}$ in engineering. International Journal of Doctoral Studies, Vol. 11, pp. 285-304, DOI: $10.28945 / 3544$

Pálinkó, É. (2010) Fiatal kutatók életútja és szakmai identitása. (The Career and Professional Identity of Young Researchers). PhD dissertation, Budapest, BCE Szociológia és Társadalompolitika Intézet, http://phd.lib.uni-corvinus. hu/451/ [Last access 0123 2020]

Patterson, O. (2002) The last sociologist. The New York Times. https://www. nytimes.com/2002/05/19/opinion/the-last-sociologist.html [Last access: 0123 2020]

Remmik, M. - M. Karm - L. Lepp (2013) Learning and developing as a university teacher: Narratives of early career academics in Estonia. European Educational Research Journal, Vol. 12, No. 3., pp. 330-341, DOI: 10.2304/ eerj.2013.12.3.330

Spalter-Roth, R. (2007) Sociologists in research, applied, and policy settings: Bringing professionals in from the cold. Journal of Applied Social Science, Vol. 1, No. 2., pp. 4-18, DOI: 10.1177/193672440700100202.

Wattis, L. - L. James (2013) Exploring order and disorder: Women's experiences balancing work and care. European Journal of Women's Studies, Vol. 20, No. 3., pp. 264-278, DOI: 10.1177/1350506813484241 